Meta

Journal des traducteurs

Translators' Journal

\title{
Traducción dialógica decolonial. Experiencia con el pueblo maya-chuj
}

\section{Fernando Limón Aguirre et Diego Pérez Hernández}

Volume 64, numéro 1, avril 2019

URI : https://id.erudit.org/iderudit/1065328ar

DOI : https://doi.org/10.7202/1065328ar

Aller au sommaire du numéro

\section{Éditeur(s)}

Les Presses de l’Université de Montréal

\section{ISSN}

0026-0452 (imprimé)

1492-1421 (numérique)

Découvrir la revue

\section{Citer cet article}

Limón Aguirre, F. \& Pérez Hernández, D. (2019). Traducción dialógica decolonial. Experiencia con el pueblo maya-chuj. Meta, 64(1), 57-77. https://doi.org/10.7202/1065328ar
Résumé de l'article

Toutes nos connaissances sur les premiers peuples nous parviennent par la traduction. En même temps, les mésententes entre les premiers peuples et les sociétés dominantes sont accentuées par des traductions insoucieuses des différences. Nous proposons un type de traduction dialogique et décolonisatrice favorisant la compréhension entre des mondes de vie et des connaissances culturelles distinctes. Ainsi, ceux qui ne conçoivent pas la vie et les mondes de vie de la même manière peuvent arriver à se connaître, à se respecter et à s'enrichir mutuellement. Sur la base d'une expérience de traduction dialogique menée afin d'interpréter des idées exprimées en langue maya-chuj, nous proposons une réflexion analytique et méthodologique dont la prétention n'est autre que de rompre avec des inerties colonisatrices. La reconnaissance des traditions linguistiques propres aux premiers peuples garantit leur existence culturelle et les rend visibles dans leur plein sens. Nous pratiquons un type de traduction interculturelle qui brise les hiérarchies et favorise les différences. 


\title{
Traducción dialógica decolonial. Experiencia con el pueblo maya-chuj
}

\author{
FERNANDO LIMÓN AGUIRRE \\ El Colegio de la Frontera Sur, San Cristóbal de Las Casas, México \\ flimon@ecosur.mx
}

DIEGO PÉREZ HERNÁNDEZ

Nuevo Porvenir, La Trinitaria, Chiapas, México*

yakinelchuj@hotmail.com

\begin{abstract}
RÉSUMÉ
Toutes nos connaissances sur les premiers peuples nous parviennent par la traduction. En même temps, les mésententes entre les premiers peuples et les sociétés dominantes sont accentuées par des traductions insoucieuses des différences. Nous proposons un type de traduction dialogique et décolonisatrice favorisant la compréhension entre des mondes de vie et des connaissances culturelles distinctes. Ainsi, ceux qui ne conçoivent pas la vie et les mondes de vie de la même manière peuvent arriver à se connaître, à se respecter et à s'enrichir mutuellement. Sur la base d'une expérience de traduction dialogique menée afin d'interpréter des idées exprimées en langue maya-chuj, nous proposons une réflexion analytique et méthodologique dont la prétention n'est autre que de rompre avec des inerties colonisatrices. La reconnaissance des traditions linguistiques propres aux premiers peuples garantit leur existence culturelle et les rend visibles dans leur plein sens. Nous pratiquons un type de traduction interculturelle qui brise les hiérarchies et favorise les différences.
\end{abstract}

\begin{abstract}
Everything we know about first peoples has come to us through translation. It is also the case that misunderstandings between first peoples and dominant societies have been accentuated by assimilative translations. We propose a dialogical and decolonizing kind of translation able to further comprehension among different worlds of life and different cultural knowledge systems. Consequently, those who do not share values about the worlds of life or about life itself can get to know each other, to respect each other and to hope for reciprocal enrichment. Based on a dialogic interpretation of some ideas expressed in the Maya-Chuj language, we propose an analytical and methodological approach aimed at thwarting colonializing inertias. Acknowledging the linguistic traditions proper to first peoples helps to recognize their cultural existence. It also helps to make them visible while respecting their power to signify. We practice a kind of intercultural translation that undoes hierarchies and welcomes differences.
\end{abstract}

\section{RESUMEN}

Todo lo que conocemos acerca de los pueblos originarios ha pasado por la traducción. El desencuentro entre estos pueblos y las sociedades dominantes está acompañado de la carencia de traducciones que honren la diferencia. Nuestra propuesta es una forma de traducción dialógica y decolonizante que favorezca la comprensión entre mundos de vida y conocimientos culturales disímiles. Así, quienes no entienden ni la vida ni el mundo de la misma manera podrán conocerse, apreciarse y enriquecerse mutuamente. Basados en la experiencia de traducción dialógica de ideas expresadas en el idioma maya-chuj, planteamos una reflexión metodológica y analítica con propuestas para romper inercias colonizantes. Reconocemos en los recursos lingüísticos de los pueblos la potencia para 
reafirmar su existencia cultural y darla a conocer con todo su sentido. Concluimos que la práctica de la traducción dialógica decolonial favorece la comunicación entre culturas rompiendo jerarquías y reivindicando las diferencias.

\section{MOTS CLÉS/KEYWORDS/PALABRAS CLAVE}

premiers peuples, mondes de vie, connaissances culturelles, interculturalité, langues autochtones

first peoples, worlds of life, cultural knowledge, interculturality, indigenous languages pueblos originarios, mundos de vida, conocimientos culturales, interculturalidad, lenguas indígenas

\section{Introducción}

El conocimiento que hoy tenemos de los pueblos originarios se lo debemos en gran parte a la traducción. Esta aseveración detona el interés de la presente reflexión. ¿Qué se sabe de los pueblos indígenas? Suponiendo una respuesta que afirme: sé tal cosa, una primera cuestión confrontativa sería: ¿lo «sé» porque conozco que así es, mediando una experiencia vital, convivencial y empática, desprejuiciada y descolonizada corroborada en una comunicación dialógica en el idioma de dicho pueblo? Si no ha sido así, las preguntas obvias son: ¿cuáles han sido las fuentes que me permiten «saber» lo que «sé»?, ¿qué procesos traslativos están de por medio?

Estos cuestionamientos son fundamentales dadas las prejuiciadas percepciones sobre los pueblos originarios que reproducen y profundizan las lógicas coloniales, presentes de inicio en las relaciones entre dichos pueblos y las sociedades dominantes. En el origen mismo de este desencuentro está la carencia de traducciones esmeradas que favorezcan el conocimiento, la comprensión y el aprecio por sus modos de existencia. Dado este panorama, ¿qué puede saber el conjunto de las sociedades predominantes, occidentales y occidentalizadas de los anhelos que se configuran al interior de estos pueblos, conformados desde los sufrimientos por el desprecio y la discriminación, juntamente con las dinámicas y luchas de resistencia?

Hasta antes del 1992, en que se orquestó la campaña de los 500 años de resistencia indígena, en el continente americano eran muy pocas las traducciones que circulaban dando cuenta de lo expresado por el corazón de los pueblos originarios. A partir de ese entonces se ha verificado una creciente circulación de textos indígenas que son traducciones. Con respecto al pueblo maya-chuj, sobre el que versa el presente trabajo, destacan las labores realizadas desde la creación, en aquella misma década, de la Academia de Lenguas Mayas de Guatemala y, en Chiapas, México, del Centro Estatal de Lenguas, Artes y Literatura Indígenas.

Es de destacarse que en esa misma década, en el año de 1996 en Barcelona se firmó la Declaración Universal de Derechos Lingüísticos. En ella se establece: «Todas las lenguas son la expresión de una identidad colectiva y de una manera distinta de percibir y de describir la realidad». Esta sentencia de la Declaración está fundada, entre más, sobre el siguiente Considerando:

Considerando que la invasión, la colonización y la ocupación, así como otros casos de subordinación política, económica o social, implican a menudo la imposición directa de una lengua ajena o la distorsión de la percepción del valor de las lenguas y la aparición de actitudes lingüísticas jerarquizantes que afectan a la lealtad lingüística de los hablantes. (CMDL 1996: 2) $)^{1}$ 
Dicha Declaración tuvo como antecedente otra, del 15 de diciembre de 1993 del Comité de Traducciones y derechos lingüísticos del PEN Club Internacional que proponía realizar una conferencia mundial de Derechos Lingüísticos.

Sociológicamente se ha demostrado que nuestro conocimiento de los pueblos originarios es aproximativo e impreciso. Por la lógica predominante de su construcción este conocimiento, incluido el de sus lenguas, ha resultado un mecanismo de control. Ya Montemayor (2004: 10) hizo con vigor la denuncia de los: «elementos del opresivo contexto histórico y lingüístico que se ha impuesto sobre las lenguas indígenas [...]. El dominio extranjero de las lenguas indígenas ha sido a menudo un instrumento de aniquilación o control cultural».

La lingüística y la traducción en este campo tienen una deuda enorme con los pueblos mismos y con la interculturalidad, para resolver aquella «separación originaria», la Babel a la que se refiere Ricœur (2004). Hablar de traducciones normalmente hace pensar que la textualidad expresada en una lengua específica puede ser trasladada a otra para hacerla comprensible. Esta concepción de la traducción nos parece insuficiente para un planteamiento de interculturalidad decolonial.

Nuestro interés por la interculturalidad decolonial pasa por una necesaria comprensión entre mundos de vida, que es el reconocimiento a la diversidad de formas de percibir, vivir y experimentar la realidad -muchas veces confluyentes e interactuantes-; y la atención a los ámbitos tan particulares dentro de los cuales somos comprendidos y en los que interactuamos con nuestros semejantes (Schütz y Luckmann 1973/1977).

Sin una traducción respetuosa del mundo de vida del otro no hay posibilidad de la comprensión deseada entre mundos de vida y cada cual interpreta la otredad cultural con criterios propios -reproduciendo simbólica y materialmente su propia sociedad-. Piénsese, para ejemplificar, en la distancia cultural que hay entre un mundo de vida en donde se tiene una relación intersubjetiva con el tiempo respecto de otro que no lo vive así y la dificultad traductológica que se tiene en lo tocante a ello.

Lo que da soporte a los mundos de vida (como horizontes de entendimiento) es tanto una estructura cognitiva específica como un modo de vida correspondiente y nutriente de tal cognición y de todo entendimiento (Limón Aguirre 2010). En esta comprensión, los contextos de multiculturalidad, caracterizados según Wieviorka (1997) por la tensión y el conflicto, nos compelen a esforzarnos, no sólo por deseo sino también por necesidad y principio ético, a fin de lograr la comprensión entre los mundos de vida concurrentes o en convivencia. Bajo tal entendido debemos traducir la lengua, vehículo de expresión y de comunicación, y por su conducto traducir lo medular y substancial: el modo de vida, lo que es decir, las prácticas que evidencian el sentido con que se vive, que da soporte y coherencia a la lengua, y el conocimiento cultural, que le da articulación, memoria y sentido.

Entendemos por conocimiento cultural la estructura cognitiva propia y particular de los diferentes pueblos y grupos culturales, que une memoria con esperanza, funciona como resistencia a las inercias del contexto y establece una relación dialéctica con el modo de vivir colectivo, dándole a este último un sentido (Limón Aguirre 2010). En otras palabras, debemos traducir al estilo de los escritores poscoloniales que, a decir de Sáenz (2009) en sus escritos, lo que están haciendo es traducir de una cultura a otra, y nosotros remarcamos: de una episteme a otra. 
En el marco de relaciones multiculturales, la tendencia predominante -consecuencia de una relación colonial y colonizante- es el reforzamiento de relaciones hegemónicas reproductoras de dinámicas de incomunicación entre pueblos. En prácticamente toda nuestra América está quebrada la comunicación entre los pueblos originarios y los grupos sociales mestizados, dominantes, de habla inglesa, francesa, portuguesa o española; reproduciéndose jerarquías y tendencias a la homologación de sentidos culturales.

La traducción en estas circunstancias tiene una labor prioritaria, que parte de la responsabilidad ética ante lo injusto y a favor de honrar las diferencias (teniendo en las más profundas de ellas su principal reto). Tratándose de mundos de vida diferentes el esfuerzo debe dirigirse a ofrecer traducciones no sólo interlingüísticas sino también intersemióticas ${ }^{2}$ (Jakobson 1963; Hjelmslev 1961/1980). Nuestro reto es la traducción de cosmogonías, de formas de pensamiento, de modos de vida; la realización de traducciones favorecedoras de la comprensión entre horizontes de existencia y conocimientos culturales disímiles, de manera que los pueblos que no ven ni asumen la vida y el mundo de la misma manera puedan conocerse, apreciarse y enriquecerse mutuamente.

Es con este marco de comprensión que hacemos un análisis de la práctica de traducción que hemos vivido en el marco de un proyecto de educación intercultural bilingüe con comunidades del pueblo maya-chuj, en las inmediaciones de la frontera México-Guatemala.

\section{Educación intercultural: un reto a la traducción}

El proyecto de investigación que ha dado marco a la presente reflexión y a la práctica de traducción que hemos realizado, se ha titulado Conocimiento cultural, traducción e interculturalidad, continuación de otros dos: Educación con base en conocimientos culturales para sustentar la interculturalidad entre los chuj e Interculturalidad y traducción. Hacia una educación que fortalezca la diversidad cultural ${ }^{4}$.

En el marco de estos proyectos hemos tenido relación con una decena de localidades chujes en territorio mexicano, abordando medularmente temáticas educativas. De esta manera, las opiniones y respuestas que hemos registrado y con las que trabajamos se nos ofrecieron mayoritariamente en el marco de un diálogo sobre la educación. En nuestras conversaciones y entrevistas, la gente nos ha ofrecido reflexiones críticas, así como señalamientos relativos a una hipotética y anhelada oferta educativa basada en el conocimiento cultural propio, acorde a su historia vivida como pueblo, en la consideración del territorio particular que habitan -el cual es atravesado por una frontera-, y coherente con la racionalidad específica que poseen como pueblo.

Al respecto, Schmelkes (2004: 28) advierte sobre el sistema educativo y la diversidad cultural, señalando que «[1] que suele ocurrir es que el sistema educativo, la escuela singular y el docente reproducen en el aula las desigualdades externas y convierten a la actividad educativa en una causa más de asimetría entre grupos culturales». Referirse a esta asimetría y a las relaciones tensas entre pueblos y culturas no debe llevar imagen de posible impermeabilidad entre culturas a lo largo de la historia. Toda cultura se ha construido sobre la base de sus relaciones e intercambios; no obstante, la relación de intercambios no es la de una reciprocidad propia del quid pro quo, sino que más bien se trata de relaciones constantemente tensas, donde la 
presión ejercida por las culturas subordinadas o sometidas no tiene la misma potencia que la desplegada por la cultura dominante. En cualquier caso, no debe pensarse en un purismo cultural, mas sí en esta dinámica de relaciones disparejas, sin dejar de reconocer la resistencia a siglos de colonización por parte de los pueblos originarios como algo medular. De esta forma, la presencia de pueblos como el chuj y sus condiciones actuales interpelan a cualquier política pública y a las sociedades en general, como también a cualquier esfuerzo de mediación cultural.

En tal entramado de relaciones cargadas de tensiones y conflictos, encontramos al interior de este pueblo maya, como ocurre generalmente en los pueblos originarios, familias enteras que niegan sus orígenes, sea viviendo en su propio lugar o habiendo emigrado; hay otras que ignoran sus orígenes; pero también hay muchas que con conciencia ideológica o sin ella se afirman como integrantes de su propio pueblo, independientemente y más allá de toda influencia debida a contactos e imposiciones vividos y padecidos. Este hecho, en el marco de cualquier esfuerzo por una educación intercultural bilingüe, debe ser analizado críticamente, trascendido y reorientado hacia el reconocimiento y la vitalidad cultural de cada uno de los pueblos. En ello, el idioma juega un papel de medular importancia.

De esta manera, y buscando la formulación de modelos pedagógicos acordes, con sus contenidos y sus materiales didácticos, resulta imprescindible la labor de la traducción. Así, nuestro planteamiento es que el anhelado modelo de educación intercultural bilingüe será más factiblemente puesto en práctica cuando en cada pueblo se lleve a cabo la labor de sistematizar y analizar críticamente los conocimientos culturales, así como su consecuente traducción decolonial, aportando ya textos bilingües.

\section{El pueblo chuj y sus circunstancias}

Para adentrarnos en la experiencia que ha dado marco a nuestra propuesta, debemos ofrecer algunos datos respecto del pueblo maya chuj. La historia de este pueblo ha sido vivida en un territorio que abarca desde lo más alto de la Sierra de los Cuchumatanes, en el Departamento de Huehuetenango, Guatemala hasta Comitán, en Chiapas, México. Es una zona de fría a templada, con bosques y milperíos, que marca la transición hacia la región de la selva lacandona al norte y noreste y la meseta comiteca al noroeste. Se trata de un pueblo milenario con cerca de ochenta mil personas. Más de seis mil de ellas viven en territorio mexicano en unas cuarenta localidades.

Nos referimos a un pueblo campesino que, como todos los pueblos mayas, vive una espiritualidad sustentada principalmente en su relación con la tierra. La tierra es la primera mediación en la relación del pueblo chuj con el Ser-Creador-y-Formador. Pero también vive tal espiritualidad poniendo de relieve el carácter subjetivo de todo lo existente no creado por el ser humano (lo visible en la naturaleza y los entes no visibles). Desde esta comprensión, el modo de vivir chuj ha ubicado como columna vertebral de su estructura ética al chamk'olal (respeto-amante) y al junk'olal (experiencia constructiva de la armonía), criterios ambos que evidencian su racionalidad relacional.

Este modo de vida es consecuencia de la trayectoria de vida en el territorio; con relaciones que van de la complicidad o el encono, hasta otras opresivas y discriminatorias. La historia del pueblo chuj tiene episodios de muerte y de resistencias. Entre 
los hechos más destacados de los tiempos recientes se encuentran: la guerra civil de Guatemala, con la aplicación de la abominable política de tierra arrasada que destruyó y masacró aldeas enteras, muchas de ellas del pueblo chuj; el desplazamiento forzoso y el refugio en tierras mexicanas para miles de personas; los reasentamientos y retornos para algunos tras los acuerdos de paz; y para un grupo numeroso la naturalización en el país de acogida, con el consiguiente sometimiento a las políticas de mexicanización que se venían aplicando en México a lo largo de prácticamente todo el siglo XX, equivalentes al desprecio por la cultura propia.

En cuanto a la situación lingüística, el 70\% habla su idioma koti’ (también conocido como chuj), en su mayoría es bilingüe (koti'-castellano) y sólo alrededor de un $7 \%$ es monolingüe koti'. El koti' es un idioma secularmente oral pero a raíz de los acuerdos de paz en el país centroamericano, con la creación de la Academia de Lenguas Mayas de Guatemala, se comenzó a establecer una gramática, la cual es conocida y usada por menos de un 10\% de hablantes, sobre todo jóvenes guatemaltecos. La enseñanza del koti'se da solamente en algunas escuelas guatemaltecas. En México sólo hay un par de personas que dominan la lectoescritura del koti'.

\section{Nuestra experiencia entre comunidades chujes}

La población chuj con la que hemos convivido y conversado en muchas ocasiones desde el año 2004 nos ha ofrecido con apertura y generosidad su palabra y con ella sus memorias y sus sueños. Aun identificando posiciones divergentes y en ocasiones hasta contrapuestas, la gente de estas comunidades mayoritariamente coincide en la reivindicación de lo propio ante lo ajeno así como en el anhelo de un futuro pletórico de los valores que les son fundamentales y que hasta ahora reivindican como una herencia y como algo importante.

Nuestro trabajo de traducción se ha venido realizando basado en narrativas grabadas y en conversaciones con personas del pueblo chuj, en su mayoría con ancianos y con ancianas que habitan en territorio mexicano. Estas traducciones las hemos realizado entre 2014 y 2016 (aunque nuestros trabajos comenzaron en 2003).

Las grabaciones que tenemos, siempre solicitadas y aceptadas, constituyen un porcentaje pequeño si las comparamos con todo lo vivido y conversado sin que medie grabadora alguna. Todo ello, acompañado de una reflexión constante, es el marco de comprensión y análisis de las transcripciones y de los textos registrados. Hemos hecho las grabaciones en idioma koti' (chuj) con las personas que han manifestado mayor capacidad narrativa y argumentativa, aunque algunas pocas han preferido hablar en castellano (lengua segunda). Para nuestras traducciones y análisis, se han hecho previamente las transcripciones siguiendo las bases de la gramática definida por la Academia de Lenguas Mayas de Guatemala-Comunidad Lingüística Chuj, reconocida oficialmente por el Instituto Nacional de Lenguas Indígenas de México.

Posteriormente de forma íntegra o por fragmentos, según sea el caso por la magnitud y por el contenido de las narraciones, se han hecho las traducciones, mismas que han sido leídas en sus partes medulares preferentemente en los contextos familiares de quien ha ofrecido la palabra para corroborar su contenido o, en su defecto, ante cualquier otro grupo de personas chujes bilingües. Las traducciones las han hecho las dos personas con mejor manejo gramatical del chuj en México, el coautor del presente texto y Cristóbal Pérez Tadeo, quien es licenciado en Lengua y 
cultura (por la Universidad Intercultural de Chiapas). Posteriormente los coautores del presente texto, examinando las traducciones resultantes, en caso de detectar algunos elementos que resultan inconsistentes, hemos hecho una segunda traducción basados en la revisión detallada de las expresiones en el original, confrontando con las grabaciones cuando ha sido necesario. En estos casos hemos analizado el contexto de la enunciación e igualmente hemos contrastado su contenido con lo que hemos aprendido sobre los conocimientos chujes, con sus cualidades características de intersubjetividad, de entrelazo entre memoria y esperanza, de antagonismo, de dialéctica remarcada y de expresión de un mundo de vida con la constelación de elementos de su existencia. Con esta traducción o con los fragmentos del original, ubicados en su contexto de enunciación y de comprensión, propiciamos un nuevo diálogo, sea con el mismo grupo familiar o con cualquier otro al que no le resulte extraño. Ello dependiendo del acceso a la localidad de origen. De esta manera arribamos a la traducción que reivindicamos.

\section{Interculturalidad y convivencia}

Dado que el marco del proyecto es la educación intercultural y bilingüe, así como la deliberada intensión del ejercicio traductológico, debemos ofrecer una aproximación a lo que comprendemos como interculturalidad. Mucho más que un tema académico relacionado con la antropología, la pedagogía, la traductología o con cualquier otra disciplina o área del conocimiento, la interculturalidad es sobre todo una aspiración social y un esmero por superar las asimetrías culturales. Cada área del conocimiento tiene su propia visión de ella. Los aportes emanados de cada una resultan relevantes para una comprensión constelada de todo acto constructor de tal aspiración. Igualmente constituyen aportes colaborativos para su realización.

El sustento de dicha aspiración por la interculturalidad proviene de la convicción de una coexistencia armoniosa posible, al tiempo de ser también un reto a la capacidad humana de apreciar y convivir con lo diferente. «Si hoy es tan necesario hablar sobre la capacidad humana de asegurar la convivencia entre nosotros, eso ocurre porque vivimos un período de permanente deterioro de esta convivencia», plantea Hinkelammert (2012: 175).

Lo que está en juego es precisamente la convivencia humana y de la humanidad toda con el planeta que habitamos. Nos referimos a la interculturalidad porque al vivir tiempos de globalización, de domino de la modernidad y de su encumbramiento en las lógicas posmodernas, enfrentamos tendencias a la homogeneización en gustos, deseos, consumos y necesidades tecnológicas (Wallerstein 1999/2002). Pero, paralelamente, pareciera que cualquier diferencia se convierte en norma para el logro de la distinción. En este último caso es frecuente acudir a los acervos de las diferencias localizadas en la diversidad cultural de los pueblos - cuyos contactos son exacerbados por los crecientes contactos multiculturales desde las dinámicas de la globalización- (Friedman 1989). No obstante, más que un elogio, cuando se banaliza el sentido de tales acervos y cuando se hace un uso arrogante y hegemónico de los mismos, dichos contactos multiculturales se convierten en una desvirtuación y en un acto expropiatorio.

En este escenario de interculturalidad deseable las comunidades culturales están conquistando su participación en espacios de convivencia y de bien común, de los 
que antes eran excluidos. De esta manera hacen su apuesta en el juego de «locuras» del que habla Hinkelammert (2012: 179), cuando sentencia: «Respetar la convivencia es locura si se ve desde el cálculo de utilidad propia, pero el sometimiento al cálculo de utilidad propia es locura si se lo ve desde lo indispensable de la convivencia, que incluye la naturaleza y, por tanto, el bien común». Convivencia o egoísmo resulta ser el dilema.

Es la misma condición de globalidad la que paradójicamente propicia que lo negado, excluido u ocultado aparezca en escena. Mas nos preguntamos: cómo resulta ser su entrada en escena: ¿como quien participa con papel propio y capacidad de interlocución, contribuyendo a la convivencia?, ¿o como el negado de siempre pero que ahora maltrecho ocupa un lugar allí sin voz? o, en su caso, ¿vociferando sin ser comprendido?, ¿balbuceando con voz tenue sin ser escuchado, o acaso como la confirmación de supremacías y superioridades de tipo colonial? Sociológicamente todas estas opciones son hechos y fenómenos reales, pero tratándose de la interculturalidad como aspiración nos deslindamos de las segundas opciones y nos posicionamos a favor de la primera. Así que hablar de interculturalidad como negatividad, es decir, como antagonismo al sistema excluyente, es hacerlo como crítica y como acto deseoso de transformación; en otras palabras, como aporte a la convivencia y como armonía utópica.

\section{El contexto de la frontera sur de México como reto a la traducción}

En la región fronteriza entre México y Guatemala son varios los pueblos que habitan en uno y otro de los países (chuj, q’anjobal, mam, popti', kaqchikel y mochó). Se trata de pueblos mayas con presencia ancestral y precolombina, que tienen en común el que una mayoría poblacional (a excepción de los mochó) vive en Guatemala y quienes habitan en México son identificados reiteradamente como «guatemaltecos», es decir: no naturales de México, extraños (Limón Aguirre 2008). Bajo esta lógica son objeto de sistemáticas políticas de mexicanización tendentes a quitarles reminiscencias o aspectos culturales que los vinculen con el país centroamericano (Hernández Castillo 2008). Dicho en otras palabras, es la franca tergiversación de la verdad histórica que produce como resultado paradójico que los aborígenes resultan considerados como los advenedizos. Este hecho ha estado acompañado por un proceso agresivo de prohibición y extirpación de las formas visibles de adscripción e identidad étnica: vestimenta, idioma, prácticas religiosas públicas correspondientes a su espiritualidad... Lo menos permitido es su reterritorialización y la vigorización de su idioma siempre buscará ese derrotero.

Un hecho elocuente de las lógicas colonizantes y de desprecio es el número prácticamente nulo de personas no pertenecientes a estos pueblos que, habitando la misma región, conozca sus idiomas y establezca con ellos una relación de interaprendizaje. Luego entonces, las relaciones establecidas para con ellos, incluyendo agentes gubernamentales: profesores, personal médico o de administración de justicia, entre otros, están basadas en el desconocimiento y en el prejuicio.

Nos resulta fundamental romper esta lógica de barreras y desconocimientos. Pero la comunicación entre culturas y entre pueblos cuyos idiomas son distintos es sumamente difícil, mayormente si se pasa por políticas y dinámicas de dominación y colonización. En esta relación la traducción ha sido principalmente en una sola 
dirección: ha sido la textualidad propia de las sociedades dominantes la que se ha traducido a las lenguas de estos pueblos originarios. Ello resulta acorde a la colonialidad del poder, fortaleciendo la colonialidad del saber (Lander 1993). El ejercicio de la traducción y la traductología misma están en deuda con estos pueblos para revertir las tendencias y tienen el reto de buscar nuevas y justas formas de equilibrio en las relaciones, apostando a la interculturalidad y al interaprendizaje.

\section{Traducción dialógica decolonial}

Como ya ha sido argumentado (Limón Aguirre 2012, 2013), la traducción que apuesta a la interculturalidad está compelida a ser una forma de actuación con apego a un anhelo y a una convicción de realizar la convivencia que rompa toda supremacía. Para ello y en nuestro caso, se requiere primeramente conocimiento profundo de una cultura que ha sido dominada y sobre todo despreciada, distinguiendo su cualidad de insubordinada; $y$, enseguida, se requiere de una complicidad ética con el texto original, de manera que éste logre irrumpir con toda su potencia y con la libertad plena de su expresión, misma que se manifiesta en su contenido y su sentido.

Este tipo de traducción debe tratar de superar l'épreuve sobre la que reflexiona Ricœur (2004), tomando a Berman, y hacer frente a las oposiciones y obstáculos provenientes de las lógicas excluyentes de la colonialidad y el poder; por lo cual es descolonizante. Tomar este posicionamiento ayudará a quien se expresa a darse a conocer, a darse a entender frente a quien muy factiblemente tenga prejuicios e, incluso, no tenga la mejor actitud en su acercamiento, ni disposición a una comprensión empática, mucho menos de aprendizaje. No debemos subestimar la resistencia del lector y el etnocentrismo lingüístico como nos lo advierte Ricœur (2004). Quien recibe, por su parte, será ayudado a lograr un mejor entendimiento del mundo que habita, para respetar y apreciar lo ajeno, hacerse prójimo, apreciar la alteridad y verse a sí mismo como un otro (Levinas 1971/2002, traducido por Miguel García-Baró). Ese otro, el lector, como lo estimula Schleiermacher (1813/2000), podrá ver al otro a través de las formas lingüísticas de aquel, y así vivirá lo diferente.

En el diálogo intercultural «el resultado es que el otro, con quien se habla y a quien se le transmiten conocimientos, experiencias, convicciones, etcétera, se interesará de lo que ahora no sabe y que no tiene ni idea. Se estará nutriendo» (Limón Aguirre 2012: 39). Estará conociendo de manera directa, descolonizadamente, sorprendiéndose y gozando con lo des-cubierto; también se estará insubordinando.

Ante los enormes retos de una traducción entre mundos de vida, y en contrasentido a las traducciones etnocéntricas con tendencias racistas y excluyentes que mantienen en el silencio a los pueblos, esta traducción decolonial no debe perder de vista que las palabras en uso cotidiano concernientes a la relación en juego están cargadas de asignaciones prejuiciadas, son reproductoras de jerarquías y renuevan y fortalecen los estigmas; piénsese tan sólo en las categorías predominantes en América Latina de indio e indígena para remitirse a las personas de los pueblos originarios, y sus imágenes asociadas de estarse refiriendo a seres arcaicos y en pobreza. En este marco decolonial, caracterizado de acuerdo a Escobar (2005) por enfrentar las grandes narrativas modernistas con apertura a modos de pensamiento no euro-céntricos, nuestra traducción se responsabilizará de que las traslaciones de los conceptos y nociones claves del conocimiento cultural del pueblo bajo sometimiento se hagan 
con cuidado, para no amputarles la potencia contenida en su propia inescrutabilidad $\mathrm{y}$ en su sentido alterno de existencia.

Bajo estas premisas resulta fundamental, en nuestra intención intercultural, la propuesta del dialogismo, trabajado en sus respectivos ámbitos por Freire y por Bajtin. Freire (1970/1974: 103) ve al diálogo como imprescindible «para la tarea común de saber y actuar [... remarcando que éste] se rompe si sus polos (o uno de ellos) pierde la humildad». En la teoría dialógica, dice Freire (1970/1974: 216 y 217), «hay sujetos que se encuentran para la pronunciación del mundo, para su transformación»; lo que «exige el descubrimiento del mundo». Veremos que esto resulta fundamental en nuestra experiencia de traducción.

Bajtin (1975/1982, 1975/1989, 1979/1986), por su parte, propone ubicarse en el ejercicio de la traducción como en un diálogo, nunca concluso ni concluyente, siendo fiel a la vez al autor que al receptor y de igual forma a lo impredecible. Esta invitación está acompañada de la importancia fundamental de poner atención al contexto, el cual ofrece marco de referencia al sentido del diálogo y da bases a la comprensión de que, precisamente por ser un diálogo, éste no está desprovisto de tensiones para el logro de entendimiento o de acuerdos. Se da por supuesto que cada cual en el diálogo tiene una posición particular en un entramado de relaciones contextuadas.

Lo que nuestra propuesta dialógica busca es decodificar las formas de colonialidad incorporadas y que se plasman en las traducciones inerciales. Para ello, en la propuesta metodológica que realizamos y ahora analizamos, revisamos las traducciones primeras (del chuj al castellano), en lo que es ya un diálogo intercultural (al ser los autores uno de habla castellana y otro chuj), detectando que en algunas de sus partes resultan reproductoras de inercias coloniales; entonces las confrontamos con los principios y las pautas que hemos distinguido (fruto de nuestras reflexiones también dialogadas) que caracterizan al conocimiento cultural del pueblo chuj. Sobre esta base proponemos una nueva traducción o simplemente sometemos al escrutinio de un colectivo chuj el contenido y el sentido de la idea original junto con nuestras inquietudes o cuestionamientos. Entonces se dialoga haciendo el debate de las posibilidades que correspondan al sentido de lo que se expresa, remitiéndole al contexto de su enunciación y de su comprensión. De esta manera, se arriba dialógicamente a una traducción que va en contrasentido de las lógicas de colonialidad, dando cuenta de lo propio, en disposición comunicativa.

Remitirse a los conocimientos culturales es hacerlo a un corpus cognitivo que está muy fuertemente enfrentado en su contenido, en su validez y en su vigencia, particularmente desde los espacios escolares y los medios, promotores de la modernidad y el desarrollismo con su poder hegemónico. No obstante, ante esta contextualidad avasalladora, permanece su presencia, ofreciendo un sentido profundo de existencia y orientando todas las interacciones. Por ello es que resultan ser nuestro referente obligado.

Al reconocer la contextualidad de las relaciones (de los sujetos con la historia y con lo vivido, de los sujetos con el texto original, de los sujetos con su mundo de vida), reparamos en aquellas formas que han resultado de uso corriente tras haber pasado por un proceso de introyección, oponiéndose y descalificando no sólo las formas culturales de enunciación sino sobre todo el contenido mismo de la palabra dada. Piénsese al respecto, por remitir a un ejemplo, el caso de la pérdida del sentido de sacralidad conferido a la tierra en el mundo de vida chuj, generando dificultad de 
conocerla y nombrarla como madre santa tierra -como se verá más abajo- y, de esta manera, aceptar su comercialización y destrucción.

A la traducción dialógica la vemos en concordancia con Medina Moya, Jaruata Borrasca, et al. (2010: 38), como un método reflexivo basado en una conversación progresiva, a la vez que como un recurso didáctico: «un buen recurso para hacer comprender nociones abstractas y poco familiares a través de otras ya conocidas y, por lo tanto, más accesibles», un recurso de concienciación y de transformación. Éste podría ser el caso, para también ejemplificar y seguir introduciéndonos en el conocimiento chuj, de la noción de winh ora alkal, que remite a la cualidad subjetiva que posee cada día, y más específicamente la de aquellos cuatro responsables o cargadores de los días -entre veinte- que son autoridades al ser quienes se van transfiriendo sucesivamente la responsabilidad de ser igualmente cargadores de los años. ¿Cómo hacer esto comprensible en otro horizonte cultural y cómo vigorizarlo como conocimiento que ofrece pautas al modo de vivir? En este caso, la idea es que la traducción a la que se arribe con el diálogo logre comunicar las relaciones intersubjetivas con el tiempo y, más aún, el trato respetuoso por la dignidad de tratarse de autoridades. Hablamos, en consecuencia, de un tipo de traducción que se constituye como recurso a favor de una comunicación comprensiva, transformadora y favorecedora de la toma de conciencia; una traducción virtuosa, en cuanto a que mediante ella se reformulan las ideas, la experiencia y la historia misma (Limón Aguirre 2012).

Para asentar nuestra propuesta y planteamiento de traducción dialógica decolonial, veamos un primer ejemplo. Nos remitimos al argumento dado por un anciano a un joven respecto a cómo hacer su trabajo. Como se apreciará, la traducción dialógica supera a una anterior, reproductora de posiciones coloniales y que generaba mayores dificultades para distinguir las particularidades del conocimiento cultural chuj, con su carácter antagónico, y con el consecuente desdibujamiento de la riqueza y complejidad del mundo de vida chuj.

1) Icha t'a peka anima, t'a pekataxo, yowalil skak' kan junok ko presente t'a yib'anhk'inal parake ol yaxb'ok t'ayonh, parake wach' tz'aji. Yuj chi, ayoch ko chamk'olal t'a spatik jun.

$(\text { Elnan Peles 2014) })^{5}$

a) Así como nuestros ancestros, es necesario que nosotros dejemos una ofrenda para el cielo, para que se haga verde y para que esté bien con nosotros. Por eso tenemos amor a nuestro trabajo.

(trad. Diego Pérez Hernández y Cristóbal Pérez Tadeo)

b) Como la gente antes, en tiempos pasados, es preciso (yowalil) encender un nuestro presente (una vela) a la madre naturaleza (yib'anhk'inal) para que dé resultado en abundancia (yaxb'ok), para que dé bien todo. Por eso tenemos aprecio al fruto del trabajo (spatik jun).

(trad. Diego Pérez Hernández y Fernando Limón Aguirre)

La primera traducción (1a) de esta frase nos lleva a pensar que se trata de una práctica cultural, de una forma de actuación acorde a la herencia cultural, consistente en la necesidad de dejar una ofrenda al cielo. Hasta allí se tiene una comprensión parcial del texto, pero para que se haga verde ya no, y la idea siguiente nos hace pensar que se trata de una práctica convenenciera para evitar algo malo. Esta traducción se crea sus propios obstáculos para el logro de la comunicación de lo que se expresa 
en lógica de conocimiento cultural, cuando éste es lo que al fin y al cabo constituye el aporte chuj a la aspirada interculturalidad.

Ejercitamos entonces una traducción dialógica (2a), acudiendo al texto original y cuestionándonos si expresaba lo enunciado. A través de la reflexión entre traductores y con la familia de Matal Elnan, arribamos a un acuerdo que nos parece reflejar la articulación de ideas-potencia contenidas en la frase original, la cual contenía elementos complejos, dinámicos, memorísticos, orientadores, dialécticos, relacionales y espirituales, que sabemos que son característicos del conocimiento chuj.

La traducción dialógica que quedó expone diferencias que son más que sutiles. Hablar de ancestros remite a otras personas, en cambio hablar de la gente antes es hacerlo de un nosotros antes que pide, siguiendo el consejo que enseguida se expresará, ser gente ahora. La idea de que algo es necesario tiene un matiz que la debilita respecto de algo que precisa para un fin determinado. Igualmente decir que dejemos una ofrenda atenúa las formas culturales y regionales de comprender. Veamos la diferencia. Encender es el acto de iniciar un fuego en una vela, que se hace hincado, en una actitud humilde y serena de mantenerse ahí y un nuestro presente evoca la cualidad proveniente de una subjetividad específica: el presente lo traemos o ponemos nosotros, en donde la vela con su fuego hace presencia; el fuego que es sagrado se hace presente con su fuerza sumando su subjetividad al nosotros. En el otro caso es el nosotros el que deja algo, una ofrenda como cualquier otra, pero rompiéndose el entrelazo, sin darle cualidad alguna y quitándole la fuerza de la voluntad del fuego allí.

Para el cielo se hace la traducción más frecuente de t'a yib'anhk'inal, ocurriendo lo mismo que en la traducción bíblica de «cielo», que se entiende en el castellano comúnmente como algo no terreno, un lugar, algo por encima del mundo, sin claridad de dónde empieza y dónde acaba; es etéreo pero a la vez es un objeto de color azul celeste, en oposición a cualquier subjetividad. En este último caso la comprensión exegética de «cielo» hace referencia a la presencia de Dios, al espacio-momento donde se obra el bien, a la práctica de Jesucristo o al lugar-acto de la construcción del Reino de Dios. Sin pretender ser un exegeta, sirva el ejemplo para comprender que en el caso chuj el yib'anhk'inal es tierra y cielo en conjunto, sin separación; todo lo que allí hay como vida; es la naturaleza viva o lo que se vive como vida (a diferencia de cualquier otra racionalidad que condujese a vivir o entender algunas «cosas» como inertes). Por ello es diferente decir: a la Madre Naturaleza, porque por un lado es la vida (en ella estamos, de ella somos parte) y por el otro porque es madre, con quien se tiene un entrelazo indisoluble; y en esa asociación está la vida toda en la vida vivida (ahuyentando alienaciones).

Enseguida, la traducción: dé resultado, a diferencia de la idea: para que se haga verde, que acude a la raíz yax, es decir: verde, con una connotación semiótica entre los chuj debido a la imagen clara de que una semilla que ha germinado se pone verde, se debe a que el vocablo yaxb'ok se usa tanto para plantas como para animales e incluso para las personas cuando a través del seguimiento a los consejos se logra el futuro. Un ejemplo de su uso es cuando se le ponen huevos a la gallina, una vez que ésta se ha echado, para que los empolle esperando que yaxb'ok, para que todos «revienten», entonces hace referencia al deseo de que algo se logre, que rinda frutos abundantes como gracia. Se desea que dé resultado como consecuencia de haber hecho lo adecuado para tal logro, pero al mismo tiempo reconociendo que, de dar 
resultado después de lo impredecible, se estará recibiendo la gracia, como cuando se siembra y se espera la gracia de la lluvia.

Finalmente amar nuestro trabajo, formulación típicamente occidental, difiere de la expresión cultural intersubjetiva y relacional de apreciar el fruto del trabajo (spatik jun), que es una valoración no por el (¿resultado del?) trabajo en sí, sino al fruto del esfuerzo, es la dimensión siempre esperanzada por aquello que se reproduce gracias al esmero.

Todos estos aspectos que ahora remarcamos como diferencia entre las traducciones fueron aspectos, entre otros hacia los que iba derivando el diálogo, que se debatieron. Esta experiencia dialógica nos ponía en evidencia los «descubrimientos» que se estaban suscitando, como lo advirtiera Freire, y aquella «fidelidad a lo impredecible» que va conjuntamente con la recreación de significados, remarcada por Bajtin.

Como se aprecia, la traducción dialógica se esmera en no desdibujar los elementos más característicos del conocimiento cultural contenidos en la frase, sino, destacarlos. En este caso vemos el entrelazo entre pasado, presente y futuro, entre nuestra vida humana y la vida global, entre la actitud humilde y la consecución de la condición deseada, entre la acción conducente y la expectativa; entre el mundo divino y el mundo del esfuerzo, entre el acto y la esperanza, entre el dar y el recibir. Dialécticas típicas del conocimiento chuj.

\section{Traducción de enunciaciones que expresan conocimiento chuj}

Para adentrarnos en la materia de nuestras traducciones, debemos anticipar que veremos formas discursivas correspondientes, algunas, a la esfera de lo religiosoespiritual y otras a la de la cotidianidad, particularmente a interacciones de transmisión de saberes (recordando que el marco de la enunciación es nuestro interés por la temática educativa). Ambas son ámbitos que ofrecen los contextos socio-culturales de producción de significados. Un asunto importante a aclarar es que entre los chuj la esfera de lo religioso, aunque tiene sus espacios más propicios donde su lenguaje se hace preciso y hasta misterioso (o sea, los géneros secundarios en la propuesta bajtiniana dada su complejidad, con independencia de que en este caso no sea lenguaje escrito), sus destellos tocan aspectos de la vida cotidiana (géneros primarios): las enseñanzas de los valores orientadores, las prácticas sanadoras, las prácticas productivas, entre más.

El que el destinatario en el contexto de la enunciación sea un miembro de la misma comunidad cultural que cuestiona, para recibir una formación o para obtener una aclaración, genera una oportunidad para brindar explicaciones que pueden trascender hacia áreas de interculturalidad, dado su carácter orientador, expositivo y/o aclaratorio.

En cualesquiera de los casos, se trata de enunciados pletóricos de expresividad y de intencionalidad. Son expresivos principalmente porque están comunicando los conocimientos culturales, como pautas de sentido a la existencia. Y tienen una intencionalidad, puesto que además de tender un puente dialógico ofrecerán premisas o bases orientadoras de las acciones y de los significados culturales en cuestión.

Analicemos, entonces, algunos ejemplos de traducciones que habiendo sido aceptadas en primera instancia, luego de pasar por el diálogo crítico y el tamiz de los conocimientos culturales, reparamos en que contenían inercias colonizantes, como 
la pérdida de riqueza y de complejidad del mundo de vida chuj; por lo tanto debían ser modificadas para hacerlas acordes al sentido de su enunciación. Dichas inercias recurren a formas que nublan las particularidades del conocimiento cultural chuj con su carácter antagónico. Para eliminarlas realizamos las respectivas traducciones dialógicas que nos ofrecieron la posibilidad de poder revelar la negatividad, evidenciando la dialéctica de la existencia chuj.

2) To icha t'a peka k'inal, yik tiempo tax yik chi, skak' tzun jun ko kantela, b’aj kal munlajel tzonh em kuman. Sko k'anan t'a ko mam yos t’a ko nun santo tierra, parake mero sto sko... ayoch ko pixan t'a spatik jun, sko chamk'olej ko munlajel chi, para ke ay ko munlajel wach', wach' olonh b'at t'a ko sat b'ati.

(Elnan Peles 2014)

a) Como en el tiempo pasado, desde hace mucho tiempo, prendemos una nuestra vela y nos hincamos en nuestro trabajadero [la milpa, la hortaliza]. Le pedimos a nuestro padre Dios y a nuestra santa madre tierra que tenemos puesto el corazón en ellos, tenemos puesto nuestro aprecio (esperanza) en ellos, para que tengamos un buen trabajo y nos va bien en nuestro futuro.

(trad. Diego Pérez Hernández y Cristóbal Pérez Tadeo)

b) Como en el tiempo pasado, hace ya mucho tiempo, prendemos una nuestra vela y nos hincamos en nuestro trabajadero [la milpa, la hortaliza]. Pedimos a nuestro padre Dios, a nuestra madre santa tierra, para que mero mantengamos nuestro corazón (to ayoch ko pixan) en ellos mismos, demostrando así que tenemos aprecio al fruto del trabajo; para que tengamos buen trabajo y que estemos preparados (wach' olonh b'at) para nuestro futuro.

(trad. Diego Pérez Hernández y Fernando Limón Aguirre)

Llamaríamos inercial la primera traducción del ejemplo 2, que se ve en 2a. Con la traducción dialógica, este enunciado quedó de la manera mostrada en $2 b$. Observamos que el inicio es prácticamente igual. Lo que hay que destacar en él son dos aspectos: primeramente la remisión al tiempo pasado, en el cual -según el conocimiento chuj- tiene sustento la visión y la relación sagrada con la vida y con las cosas de la vida; y un segundo aspecto corresponde a la relación reverencial con la tierra, que se expresa en la acción de hincarse en el lugar mismo donde se hará el trabajo campesino, trabajo para la subsistencia.

Este inicio que habla de la acción empírica de hacer una oración antes de iniciar los trabajos, hincándose y encendiendo una vela, da pauta a la aclaración subsiguiente. Pero comiéncese distinguiendo la intención del acto. Según la primera traducción se entendería que es para que tengamos un buen trabajo y nos vaya bien en nuestro futuro. Según la traducción posterior al diálogo y la reflexión decolonial se entiende con mayor facilidad que el objetivo de dicha acción es para mantener nuestro corazón en..., lo que, a nuestro parecer, honra más la idea que pauta la acción. La primera traducción exponía la idea de tener puesto el corazón en... cuya imagen pareciera encontrar coherencia con la siguiente idea: tener puesto nuestro aprecio en..., asociada en la frase al futuro y por eso, quienes tradujeron pusieron entre paréntesis «esperanza»-de que ellos: nuestro padre Dios y nuestra santa madre tierra, derramen bendiciones-. En ella la idea última remite al futuro como una expectativa o rumbo del derrotero, con una asociación igualmente lamentable de exponer a un sujeto cuya relación con su trabajo es alienada, lo cual no corresponde en ninguno de los casos al conocimiento chuj del tiempo y de las consecuencias del trabajo. 
En sentido cultural la idea de mantener nuestro corazón en algo significa lo opuesto a olvidar. Quiere decir que se está hablando del recuerdo como memoria, en contraposición a dejar algo en el olvido. El recuerdo debe ser sostenido. El asunto medular es la memoria que ciertamente tendrá su entrelazo con el futuro, de modo que si ya no se mantiene con conciencia y convicción el corazón en aquello apreciado la posibilidad de futuro queda totalmente trastocada. Esto difiere de la noción de tener el corazón puesto en algo, como un depósito en una ilusión, por puro aprecio.

Hay otro aspecto del conocimiento cultural trastocado en la primera traducción, el que refiere a la relación con el trabajo. Con el acto de hincarse y pedir se demuestra que se tiene aquella valoración que decíamos al fruto del trabajo; se demuestra ante Dios y ante la tierra, pero también ante quien pueda ser testigo de dicha actitud. Esto significa también que se pide con la actitud adecuada.

La segunda imagen está íntimamente asociada a la primera. La traducción primera parece moverse en una relación nomológica, interesada, de causa efecto: si yo hago lo correcto o adecuado es para la conducción hacia un fin: nos va bien. La típica racionalidad racional occidental que, en concordancia con una temporalidad lineal, progresista, predominante en el contexto, establece una asociación inmediata con el fin deseado: para que nos va bien en nuestro futuro. Hago lo correcto para que nos vaya bien (no se desdibujó la lógica colectiva). En cambio en el conocimiento chuj, si hacemos lo conducente es para que estemos preparados; y por eso mismo se constituye en una intención. No es hacer lo adecuado y sentarse a esperar a que el futuro llegue y que en ese momento nos vaya bien, sino hacer lo conducente para adquirir, para contar ya con una disposición; de esa manera estamos anticipando el futuro como resultado de nuestra actitud y nuestro esmero. Ésa es la esperanza: el futuro deseado está ya en nuestra disposición y en nuestra acción.

Ahora, con base en esta traducción dialógica quedan expuestos tres criterios del conocimiento chuj, que en este caso sustentan el hacer la oración, hincándose y encendiendo la vela: 1) el recuerdo y el no olvido, 2) el trabajo y la actitud para el logro de buenos frutos y 3) le preparación de sí mismo para la vida. El no olvido se asocia al consejo de no endiosarse como seres humanos, ni asumir que no se necesitan las fuerzas divinas, provenientes una de Dios y otra de la tierra, que es nuestra madre y que es santa, por lo que se acordó que la mejor traducción es: nuestra madre santa tierra. De acá, inclusive se desprende otro detalle destacado de la traducción desde la disposición dialógica, pues resultó remarcándose que la tierra es santa y por ello la asociación nominal es: santa tierra, con una exaltación a su subjetividad.

Veamos ahora como un segundo ejemplo la traducción de otra frase relativa a la obscuridad. Ésta hace referencia a la experiencia histórico-fenoménica del pasado, como igualmente se experimenta en la dialéctica de la in-satisfacción de lo deseado.

3) K'ik'al k'inal ayonh ek'i. Aton aton k'ik'al k'inal chi, icha peka tiempo yik tax ixonh pitzwi ha'ontik. Hi mas pi'or icha ix pitzwi ko mam ko nun. K'ik'al k'inal. Ata ay k'ik'al k'inal pekatax chi: malaj estudio, malaj b’ajtil skab' junok lolonel.

(Tunku 2014) $)^{7}$

a) Estamos en la obscuridad. La obscuridad es en aquel tiempo cuando nosotros fuimos creciendo. Y todavía es peor cuando fueron creciendo nuestros padres y madres en la ignorancia u obscuridad; ahí sí está la obscuridad en el tiempo pasado, porque no había estudio, nunca escuchamos alguna palabra.

(trad. Diego Pérez Hernández y Cristóbal Pérez Tadeo) 
b) Estamos en la obscuridad. Esto es la obscuridad. Como en el tiempo pasado cuando nosotros crecimos; y es peor cuando crecieron nuestros padres nuestras madres. Obscuridad. Allí está la obscuridad en aquel tiempo: no hay estudio, nunca escuchamos alguna palabra.

(trad. Diego Pérez Hernández y Fernando Limón Aguirre)

La traducción primera del ejemplo 3, acorde a formas corrientes de entendimiento y reproducción de imágenes e ideas contextuales y coloniales, es la que vemos en 3a. En $3 b$ encontramos la traducción dialogada. La continuación de estas frases son referencias en torno a la obscuridad, mismas que nos brindaron un contexto mayor: «Y así es el tiempo que vivimos la obscuridad, están cerrados nuestros ojos, cualquier persona te puede ofender» (3a) y "Éstas son las obscuridades que vivimos; es obscuridad. Nos atemorizamos ante los que saben ${ }^{8}$, peor ante los que poseen una capacidad de hacer el mal. Así. Se distinguen y hablan castilla» (3b). Rematando al final: «...porque sabemos muy bien que somos de la obscuridad ${ }^{9} »(3 b)$. Estas ideas no tuvieron divergencia en las traducciones y en ellas se destaca que la obscuridad no está asociada exclusivamente al tiempo pasado. Y esto resulta clave.

Comencemos poniendo de relieve la última imagen: sabemos muy bien que somos de la obscuridad. Recordemos la Cuarta Declaración de la Selva Lacandona ${ }^{10}$, el $1^{\circ}$ de enero de 1996 del Ejército Zapatista de Liberación Nacional, que expresa el sentir real, doloroso de los pueblos indígenas: «Nosotros nacimos de la noche. En ella vivimos. Moriremos en ella». Está concordante con otro texto zapatista, Las Miradas. Parte 5: Mirar la noche en que somos ${ }^{11}$. Cuando en nuestro caso el narrador chuj dice que somos de la obscuridad está exactamente haciendo esta misma asociación, como grito de dolor, pero también como concienciación y convicción de que en la dignidad y en la conciencia está la ruptura de tal obscuridad.

Aquella Cuarta Declaración de los zapatistas antes de concluir señala la redención: «Vive el ¡Ya basta! Vive la noche que se hace mañana. Vive nuestro digno caminar junto a los todos que lloran. Para destruir el reloj de muerte del poderoso luchamos». Así de clara es la asociación de que la obscuridad padecida (cualquier persona te puede ofender) es propiciada por quienes están encumbrados: los que saben, poseen [...] capacidad de hacer el mal, hablan castilla.

Estas imágenes son trascendentes como toma de posición en la historia desde la conciencia. Si la traducción no es capaz de interpretar este tipo de imágenes y de sentidos reproduce la imagen de: nuestros padres, nuestras madres y nuestro pasado «pertenecen a la oscuridad»; y, por lo tanto, sería necesario dejarlos para salir de ella. En cambio, cuando desde el diálogo se procura la criticidad y la negatividad propia del conocimiento cultural, el resultado es muy diferente y resulta no un texto de lamento sino concienciador; crítico y auto-crítico.

En la traducción primera la obscuridad está relacionada con el tiempo pasado, concretada en la idea de que se creció «en la ignorancia»; la obscuridad según esta traducción se debía a que no había estudio. De esta manera no hay sujeto productor de obscuridad, sino que es propia de una época. Una obscuridad provocada por la ausencia de un servicio o por la privación de un derecho que es el estudio. Una obscuridad causada por el hecho de no saber el castellano; es a esto a lo que se refiere al decir: nunca escuchamos alguna palabra.

La traducción dialógica reparó en cambio en que el narrador no asigna en ningún momento la obscuridad a una causa particular. La ausencia de estudio no es la causa 
de la oscuridad. La obscuridad allí está y se refleja en que no hay estudio. La obscuridad es propiciada por quienes tienen poder. Es una relación de colonialidad, opresión y exclusión. No hay estudio como consecuencia de esa relación y no al revés.

Este texto es por demás elocuente de las condiciones reales y vigentes de relaciones socio-culturales alienantes, opresivas y excluyentes: estamos en la obscuridad y esta obscuridad, de seguir en ella, se concreta en la ausencia de programas de estudio, en obstáculos a la interacción comunicativa y equilibrada y en una posición amedrentada ante otros cuya apariencia es la de no estar en la obscuridad. En estas condiciones: cualquier persona te puede ofender.

Como estamos destacando, la traducción decolonizante debe pasar por el diálogo analítico, crítico, atento a los conocimientos culturales; o también, expresado desde otra perspectiva: la disposición dialógica nos permitió lograr una traducción decolonizante.

Tenemos otro ejemplo muy elocuente de la historia colonial. En este caso el tema es la carga:

4) Atonta jun aton icha syal winh ha mam icham Xapin Mekel, tob' skuch chaj ewinh mestro tik pekataxo. ¡Soloma b’at skuch kot ewinh!, tz'och popom wakaki sja.

$\left(\right.$ Elnan Peles 2014) ${ }^{12}$

a) Por eso decía tu abuelito Sebastián: En estos tiempos se cargan a los maestros, ¡se llegan a cargar desde Soloma!, cargándolos sobre sus espaldas con mecapal.

(trad. Diego Pérez Hernández y Cristóbal Pérez Tadeo)

b) Así como dice tu abuelito Xapin Mekel, que se cargan a los maestros en esos tiempos. ¡Hasta en Soloma lo llegan a traer!, llevando sobre sus espaldas con mecapal a quien llega como una carga (wakaki).

(trad. Diego Pérez Hernández y Fernando Limón Aguirre)

La traducción desde la inercia colonial y la traducción resultante luego del diálogo se encontran en $4 \mathrm{a}$ y $4 \mathrm{~b}$, respectivamente. Fuimos aprendiendo a estar muy atentos cuando se habla del pasado, así como de las lógicas de la temporalidad y las autoinculpaciones. Por eso revisamos la frase y efectivamente procedimos a dialogar, a debatir su significado, y a ponerla en contexto confrontando el contenido de la misma con el conocimiento cultural chuj.

En la traducción primera no se quita la experiencia histórica de haber cargado personas, pero sí se desdibuja la experiencia histórica que se está denunciando del sometimiento, de haber vivido con cargas sobre de sus espaldas, en lógica de subordinación. Los maestros y con ellos sus programas eran relaciones sufridas, pues se presentaban y se experimentaban como sometimiento a una wakaki, es decir a una carga pesada que humillaba. La pura omisión de la cualidad de la carga como wakaki (ese tipo de cargas que se asumen con actitud humilde de sometimiento), está quitando la dureza de la expresión.

En otra frase muy corta, la traducción reprodujo sitios comunes en la cotidianeidad, omitiendo la categoría detonante de movimiento:

5) Por eso, icha t'a kinhatil ha'on tik, ni ha'on icha t'ako parte, manh kojtakok laj estudio.

$(\text { Pais 2014) })^{13}$

a) Por eso, como indígena que somos, para nosotros no hay estudio.

(trad. Diego Pérez Hernández y Cristóbal Pérez Tadeo) 
b) Por eso, por nuestras raíces indígenas, como nosotros, desconocemos si hay estudio.

(trad. Diego Pérez Hernández y Fernando Limón Aguirre)

El ejemplo 5 se tradujo primeramente como en $5 \mathrm{a}$. Y entrando en un diálogo nuestra traducción (5b) remarcó que la idea de kinhatil ha'on tik refiere a algo seminal, de origen o a tener raíces en algo. Esta traducción nos lleva a la idea de que había una lógica de límite o alcance de los programas escolares, que efectivamente se nos ha confirmado, pero en este caso se trata de una expresión denunciativa que comunica que hubo un ocultamiento. Es la misma lógica de exclusión pero cimentada además en el ocultamiento. Ya hay, en adición, otro motivo de denuncia.

Retomando la idea de kinhatil cabe hacer mención que la frase bien puede ser traducida como por ser semilla, como nosotros, o, incluso como se aproximó la primera traducción como indígenas-semillas que somos. De cualquier forma se estaría poniendo de relieve el ser semilla, partícipes de la fecundidad y la ancestralidad propia de los pueblos originarios.

\section{Reflexiones}

Expuestos estos ejemplos que nos han permito ver las no tan sutiles diferencias entre traducciones, distinguimos la importancia de cuidar la traducción, asunto que cobra relevancia y trascendencia tratándose de idiomas de pueblos colonizados, puesto que o se dirige a favor o se dirige en contra de la perpetuación de la colonialidad del saber y del ser. En nuestro caso, la traducción dialógica nos permitió rescatar las formas dialécticas, críticas y de intersubjetividad que están contenidas en el conocimiento chuj y que encuentran formas de expresión en su propia lengua.

Este trabajo corrobora lo denunciado por Montemayor (2004) cuando se refería a la instrumentalización de las lenguas indígenas como mecanismos de control cultural, pero al mismo tiempo la invitación a reparar en la reafirmación lingüística para el fortalecimiento de la memoria comunitaria. Los pueblos tienen en los recursos de su propia lengua los elementos necesarios para reafirmar su existencia cultural y darla a conocer tal y como se vive. Desde esta premisa la traducción que se hace instrumento de la interculturalidad no sólo favorece una comunicación entre diferentes modos de vida, sino que también reivindica el sentido verdadero de la misma, que es precisamente tal diferencia.

Se evidencia que dar cuenta de lo propio y explicarlo es un prerrequisito para la interculturalidad; que sólo será posible a través de un diálogo verdadero. Quien traduce, cómplice en este diálogo, ha de saber asumir y aceptar la diferencia insuperable de lo propio y lo extranjero, pero no como problema, sino como su trabajo, su reto y su derrotero. Pero para eso es necesaria una educación traductológica crítica, como lo plantea Gólcher Coto (2004: 80): «ya que pretende que los estudiantes sean capaces de hacerse y contestarse a sí mismos preguntas acerca de lo que hacen, cómo y por qué lo hacen». Para esta autora el asunto fundamental es la conciencia de parte de quien traduce de lo que está haciendo.

Por nuestra parte hemos aprendido que con una disposición dialógica la comunicación de los conocimientos culturales de los pueblos enriquece la toma de conciencia de las relaciones de dominación y la importancia de su transformación hacia unas de tipo intercultural utópico; máxime tratándose de la posibilidad de elaborar 
materiales educativos que puedan ser de utilidad en una educación de tal tipo. El interés principal de la acción y/o la actitud dialógica es ir en profundidad en pos de una afirmación verdadera compartida que desvele las condiciones de la existencia; es entenderse entendiendo, concienciarse concienciando, transformarse transformando.

Este tipo de traducciones nos ha ofrecido un nuevo tipo de relaciones con el mundo de vida chuj, no de curiosidad ni de violencia, sino de amorosa complicidad, que denota una opción-interpretación de la idea, que deja traslucir una atinada opción personal, aportada por el contexto del traductor. Con base en ello afirmamos que la función de la traducción dialógica decolonial será la de ejecutar la esperanza de la interculturalidad desde el colonizado; esto es, realiza una función amorosa y convivencial, comunicando el sentido de existencia de una colectividad humana a miembros de otra para que la conozcan y así la respeten-amantemente.

Es importante reparar en la temporalidad, puesto que ésta marca una diferencia fundamental entre racionalidades distintas. Para nuestro caso ha sido importante la actualización del cronotopo desde la memoria, como entrelazo de lo acontecido con el presente; es en él en donde la conciencia del aquí y ahora se proyecta temporal y espacialmente, recuperando como un hipérbaton la memoria del pasado hasta el futuro.

Esta propuesta de traducción ha comenzado a generar frutos de encuentro, de diálogo, de reflexión al interior de la comunidad chuj. Ha también comenzado a ofrecer formas más asertivas de exposición de lo chuj ante la gente de otros horizontes culturales, pero será materia de trabajos futuros el analizar la recepción a estas traducciones. Esperamos hacerlas en el ámbito educativo, pero al mismo tiempo en el de las relaciones cotidianas en la región que habitamos. También será importante conocer la acogida que pueda tener este planteamiento entre los otros pueblos mayas de la región.

Finalicemos con dos citas de Sáenz (2009: 768) a la mestiza cultural y racial Malika Embarek ${ }^{14}$, quien al hablar de sus «arabismos preferidos» dijo: «consultemos el tesoro de nuestra lengua, antes de sucumbir perezosamente al encanto de los términos foráneos». La vigilancia de lo propio colonizado no es fácil pero es fundamental para toda propuesta de interculturalidad, que en ningún caso es el desdibujamiento de las fronteras culturales, sino la disposición al diálogo, la equidad y la justicia entre diferentes. Sáenz (2009: 771) concluye su texto diciendo: «porque el traductor es, debe ser, no sólo un puente entre culturas sino también un defensor de las fronteras de la cultura».

\section{AGRADECIMIENTOS}

Agradecemos el financiamiento del Fondo Sectorial SEP-CONACYT al proyecto 189575.

\section{NOTAS}

* Diego Pérez Hernández es miembro del pueblo maya-chuj y no tiene afiliación institucional.

1. Conferencia Mundial de Derechos Lingüísticos (1996): Declaración Universal de Derechos Lingüísticos. Barcelona: Organización de las Naciones Unidas. Consultado el 21 de marzo de 2017, <https://www.inali.gob.mx/pdf/Dec_Universal_Derechos_Linguisticos.pdf >

2. Las traducciones intersemióticas se han expandido a múltiples diálogos que rebasan los típicos de la literatura, el cine, el comic, la música, la danza y para nosotros debe llegar al ámbito socioantropológico y de las relaciones multiculturales. 
3. Apoyado por el Consejo Nacional de Ciencia y Tecnología y la Secretaría de Educación Pública de México.

4. Apoyado económicamente por el Grupo de Trabajo México-Quebec y el cual contó con la codirección del Prof. Georges L. Bastin de la Universidad de Montreal.

5. Elnan Peles, Matal (25 de agosto de 2014): comunicación oral. Nuevo Porvenir, La Trinitaria, Chiapas.

6. Elnan Peles, Matal (25 de agosto de 2014): comunicación oral. Nuevo Porvenir, La Trinitaria, Chiapas.

7. Tunku, Kuxin (27 de mayo de 2014): comunicación oral. Santa Rosa el Oriente, La Trinitaria, Chiapas.

8. Se refiere a las personas no indígenas con imagen de cierta autoridad.

9. Esta frase hace pensar en la que expresara el EZLN al decir: «de la noche somos».

10. Comité Clandestino Revolucionario Indígena-Comandancia General del EZln (1 de enero de 1996): Cuarta Declaración de la Selva Lacandona. México: Ejército Zapatista de Liberación Nacional. Consultado el 27 de diciembre de 2015, <http://palabra.ezln.org.mx/ comunicados/1996/1996_01_01_a.htm>.

11. Comité Clandestino Revolucionario Indígena-Comandancia General del EZLN (13 de febrero de 2013): ELLOS Y NOSOTROS. VI.- Las Miradas. Parte 5: Mirar la noche en que somos. (De la luna nueva al cuarto creciente). Enlace zapatista. Consultado el 5 de agosto de 2016, <http:// enlacezapatista.ezln.org.mx/2013/02/13/ellos-y-nosotros-vi-las-miradas-parte-5-mirar-la-nocheen-que-somos-de-la-luna-nueva-al-cuarto-creciente/>.

12. Elnan Peles, Matal (25 de agosto de 2014): comunicación oral. Nuevo Porvenir, La Trinitaria, Chiapas.

13. PaIs, Palas (17 de junio de 2014): comunicación oral. Nuevo Progreso, La Trinitaria, Chiapas.

14. Malika Embarek es una traductora especializada en literatura magrebí de expresión francesa y quien, desde su propia experiencia reflexiona la traducción de elementos lingüísticos y culturales específicos de una cultura, como un contacto con sus propias raíces, como traducirse a sí misma.

\section{REFERENCIAS BIBLIOGRÁFICAS}

Bajtin, Mijail (1979/1986): Problemas de la poética de Dostoievski. (Traducido del ruso por Tatiana Bubnova) México: Ed. Fondo de Cultura Económica.

Bajtin, Mijail (1975/1989): Teoría y estética de la novela. Trabajos de investigación. (Traducido del ruso por Helena S. Kriúkova y Vicente Cazcarra) Madrid: Taurus.

Bakhtin, Mikhail (1975/1982): The Dialogic imagination: Four Essays. (Traducido del ruso por Caryl Emerson y Michael Holquist) Austin: University of Texas Press.

Escobar, Arturo (2005): Más allá del Tercer Mundo. Globalización y diferencia. Bogotá: ICAN. Freire, Paulo (1970/1974): Pedagogía del oprimido. (Traducido del portugués por Jorge Mellado) 13a ed. México: Siglo XXI.

Friedman, Jonathan (1989): Culture, Identity and World Process. Review. 12(1):51-69.

Gólcher Cото, Ingrid (2004): Educación del traductor como pensador crítico. Revista Letras. $1(36): 65-80$.

Hernández Castillo, Rosalva Aída (2008): Procesos contemporáneos de conformación de identidades indígenas en la frontera sur de Chiapas. Mexico: Comisión Nacional para el Desarrollo de los Pueblos Indígenas.

Hinkelammert, Franz (2012): Lo indispensable es inutil: hacia una espiritualidad de la liberación. San José de Costa Rica: Editorial Arlekín.

Hjelmslev, Louis (1961/1980): Prolegómenos a una teoría del lenguaje. (Versión española de José Luis Díaz de Liaño) 2a ed. Madrid: Gredos.

Jаковson, Roman (1963): Essais de linguistique générale. Tome I. Paris: Minuit.

LANDER, Edgardo, comp. (1993): La colonialidad del saber: eurocentrismo y ciencias sociales. Perspectivas latinoamericanas. Buenos Aires: CLACSO.

Levinas, Emmanuel (1971/2002): Totalidad e infinito. (Traducido del francés por Miguel García-BAró) Salamanca: Sígueme. 
Limón Aguirre, Fernando (2008): Ciudadanía del pueblo chuj en México. Una dialéctica negativa de identidades. Alteridades. Multiculturalismo, derechos humanos y pueblos indígenas. 18(35):85-98.

Limón Aguirre, Fernando (2010): Conocimiento cultural y existencia entre los chuj. México: CDI.

Limón Aguirre, Fernando (2012): Interculturalidad y traducción. Retos al entendimiento y la comunicación. Tinkuy. Boletín de investigación y debate. 20:92-100.

Limón Aguirre, Fernando (2013): Por una traducción constructora de interculturalidad en contextos indígenas. In: Nayelli CaStro Ramírez, ed. Traducción, identidad y nacionalismo en Latinoamérica. México: Bonilla Artigas Editores/Consejo Nacional para la Cultura y las Artes, 253-282.

Medina Moya, José Luis, Jaruata Borrasca, Beatriz e Imbernon Muñoz, Francesc (2010): La enseñanza reflexiva en la educación superior. Cuadernos de Docencia Universitaria. Barcelona: ICE/Eds. Octaedro.

Montemayor, Carlos (2004): Pasado y presente de la escritura en lenguas indígenas. In: Carlos Montemayor y Donald Frischmann, eds. Words of the true peoples: anthology of contemporary Mexican indigenous-language writers. Austin: University of Texas Press, 8-15.

Riccur, Paul (2004): Sur la traduction. Paris: Bayard.

SÁenZ, Miguel (2009): Traducción y cultura en el ámbito literario. Entreculturas. 1:763-771.

Schmelkes, Sylvia (2004): Educación intercultural. Reflexiones a la luz de experiencias recientes. Revista Electrónica Sinéctica. 23:26-34.

Schleiermacher, Friedrich (1813/2000): Sobre los diferentes métodos de traducir. (Traducido del alemán por Valentín García Yebra) Madrid: Gredos.

Schütz, Alfred y Luckmann, Thomas (1973/1977): La estructura del mundo de vida. (Traducido del inglés por Nestor MinguÉs) Buenos Aires: Amorrortu.

WALLERSTEIN, Immanuel (1999/2002): Conocer el mundo. Saber el mundo. El fin de lo aprendido. (Traducido del inglés por Stella Mastrangelo) México: Siglo XXI/CIICH-UNAM.

Wieviorka, Michel (1997): Culture, société et démocratie. In: Michel Wieviorka, ed. Une société fragmentée? Le multiculturalisme en débat. París: La Découverte, 9-60. 